\title{
Transesterifikasi Minyak Kelapa Sawit menggunakan Katalis Kalsium Oksida (CaO) menjadi Biodiesel
}

\author{
Presyta Chalida Eka Putri dan Edy Supriyo \\ Program Studi Teknologi Rekayasa Kimia Industri Sekolah Vokasi Universitas Diponegoro \\ Jl. Prof. H. Soedarto, SH., Tembalang, Semarang, 50275, Indonesia \\ Emai: presyta.chalida2807@gmail.com
}

\begin{abstract}
Abstrak
Bioedisel merupakan bahan bakar alternatif yang menjanjikan yang dapat diperoleh dari minyak nabati maupun lemak hewani melalui reaksi transesterifikasi dengan alkohol. Minyak nabati mempunyai potensi yang cukup besar untuk bahan bakar alternatif mesin diesel dengan dilakukan reaksi transesterifikasi. Penelitian ini dilakukan untuk mengetahui pengaruh suhu $\left(55^{\circ} \mathrm{C}\right.$ dan $\left.65^{\circ} \mathrm{C}\right)$, konsentrasi katalis $(3 \%$ dan $5 \%)$ dan $\%$ berat metanol (30\% dan $50 \%$ ) terhadap yield metil ester yang dihasilkan dan dilakukan optimasi proses dengan variasi variabel suhu transesterifikasi untuk menentukan besar yield biodiesel minyak kelapa sawit. Dari penelitian didapatkan suhu transesterifikasi optimum adalah $60^{\circ} \mathrm{C}$ dengan yield sebesar $89,98 \%$ untuk konsentrasi katalis $3 \%$ dan $50 \%$ berat metanol. Biodiesel yang didapatkan memiliki densitas sebesar $838 \mathrm{~kg} / \mathrm{m}^{3}$ (standar Pertamina 815-860 kg/m³), viskositas sebesar 4,01 mm²/sec (standar Pertamina 2,0 - 4,5 $\mathrm{mm}^{2} / \mathrm{sec}$ ), bilangan asam sebesar $0,45 \mathrm{mgKOH} / \mathrm{gr}$ (standar Pertamina maks 0,6 ), flash point sebesar $63^{\circ} \mathrm{C}$ (standar Pertamina min $52^{\circ} \mathrm{C}$ ) dan angka setana sebesar 48,45 (standar Pertamina min 48). Serta pengaplikasian biodiesel dengan uji kebisingan biodiesel (B30) minyak kelapa sawit pada mesin fogging sebesar 79,9 dB dan pada kebisingan solar pada mesin fogging sebesar 81,6 dB.
\end{abstract}

Kata kunci: biodiesel, minyak kelapa sawit, transesterifikasi

\section{Abstract \\ Transesterification of Palm Oil using Calcium Oxide (CaO) Catalyst to Biodiesel}

Bioedicel is a promising alternative fuel that can be obtained from vegetable oils and animal fats through transesterification reactions with alcohol. Vegetable oil has a large enough potential as an alternative fuel for diesel engines with a transesterification reaction. This research was conducted to determine the effect of temperature $\left(55^{\circ} \mathrm{C}\right.$ and $\left.65^{\circ} \mathrm{C}\right)$, catalyst concentration (3\% and 5\%) and weight\% methanol (30\% and 50\%) on the yield of methyl ester produced and performed optimization of the process by varying the transesterification temperature variable large yield of palm oil biodiesel. From the research, it was found that the optimum transesterification temperature was $60^{\circ} \mathrm{C}$ with a yield of $89.98 \%$ for a catalyst concentration of $3 \%$ and $50 \%$ by weight of methanol. The biodiesel obtained has a density of $838 \mathrm{~kg} / \mathrm{m}^{3}$ (Pertamina standard $815-860 \mathrm{~kg} / \mathrm{m}^{3}$ ), a viscosity of $4.01 \mathrm{~mm}^{2} / \mathrm{sec}$ (Pertamina standard $2.0-4.5 \mathrm{~mm}^{2} / \mathrm{sec}$ ), an acid number of $0.45 . \mathrm{mgKOH} / \mathrm{gr}$ (Pertamina standard max 0.6), flash point of $63^{\circ} \mathrm{C}$ (Pertamina standard min $52^{\circ} \mathrm{C}$ ) and cetane figure of 48.45 (Pertamina standard min 48). And the application of biodiesel with the biodiesel noise test (B30) of palm oil on the fogging machine is $79.9 \mathrm{~dB}$ and the diesel noise on the fogging machine is $81.6 \mathrm{~dB}$.

Keywords: biodiesel, palm oil, transesterification

\section{PENDAHULUAN}

Indonesia merupakan kaya akan sumber daya energi seperti minyak, gas, batubara, panas bumi dan sebagainya. Beberapa laporan menunjukkan bahwa sejak pertengahan tahun 80 an terjadi peningkatan kebutuhan energi khususnya untuk bahan bakar mesin diesel yang 
diperkirakan akibat meningkatnya jumlah industri, transportasi dan pusat Pembangkit Listrik Tenaga Diesel (PLTD) diberbagai daerah di Indonesia. Peningkatan kebutuhan energi ini diakibatkan karena jumlah minyak yang merupakan andalan komoditi ekspor semakin berkurang karena dipakai untuk memenuhi kebutuhan dalam negeri yang mengakibatkan berkurangnya devisa negara. Dilain itu, di Indonesia cadangan minyak semakin terbatas karena tidak dapat diperbaharui. Maka dari itu dilakukan alternatif untuk bahan bakar tersebut. Rudolph Diesel ( \pm tahun 1900) mendemonstrasikan idenya dalam menggunakan minyak nabati sebagai pengganti bahan bakar diesel. Minyak nabati mempunyai potensi yang cukup besar untuk bahan bakar alternatif mesin diesel. Indonesia yang kaya akan sumber minyak nabati mempunyai peluang yang besar dalam mengembangkan penggunaan bahan bakar alternatif ini. Viskositas pada minyak nabati yang tinggi ini (11-17 kali lebih besar dari petroleum diesel) dan adanya asam lemak bebas dan volatilitas yang rendah mengakibatkan kendala dalam penggunaan minyak nabati sebagai bahan bakar mesin diesel ini. Maka dari itu minyak nabati perlu diubah menjadi alkil ester (biodiesel) yang bertujuan agar viskositas turun, volatilitas naik dan asam lemak bebas yang hilang ${ }^{[5]}$. Biodiesel ini tidak menghasilkan cemaran yang berbahaya bagi lingkungan. Biodiesel juga dapat digunakan dan dicampur pada minyak diesel konvensional (Hidayati et al., 2017)

Pada penelitian Aziz, 2008 didapatkan cetane number sebesar 51. Penelitian Yudhistira, (2013) didapatkan cetane number sebesar 51,73. Dan pada penelitian Tantra et al. (2011) didapatkan cetane number sebesar 57,5 - 59,9.

Bahan yang akan digunakan pada pembuatan biodiesel ini adalah minyak kelapa sawit untuk membandingkan hasil biodiesel pada minyak kelapa sawit dengan hasil biodiesel pada Pertamina. Pada penelitian ini menggunakan variabel suhu $55^{\circ} \mathrm{C}$, dan $65^{\circ} \mathrm{C}$, konsentrasi katalis $3 \%$ dan $5 \%$ dan $\%$ berat methanol 30\% dan $50 \%$. Serta dilakukan pehitungan berupa konversi reaksi.

Pada umumnya minyak goreng memiliki kandungan asam lemak bebas yang tinggi, oleh karena itu transesterifikasi minyak ini dengan bantuan katalis basa $\mathrm{NaOH}$ atau $\mathrm{KOH}$ tidak tepat.
Alternatif katalis lain adalah katalis basa padat. Penggunaan katalis heterogen (padat) memiliki beberapa kelebihan : dapat mempermudah proses pemisahan katalis dengan reaktan atau produk dengan cara filtrasi sederhana, kurang beracun dan korosif, lebih aman terhadap lingkungan (Hidayati et al., 2017).

$\mathrm{CaO}$ merupakan material yang tersedia melimpah di Indonesia dan dapat dimanfaatkan sebagai katalis untuk transesterifikasi. Selain itu harganya murah dan memiliki kelarutan yang rendah dalam metanol. Oleh karena itu, dengan berkurangnya cadangan minyak bumi maka dilakukan penelitian biodiesel dengan menggunakan minyak goreng.

\section{METODOLOGI}

Pada penelitian biodiesel ini menggunakan minyak kelapa sawit dengan katalis kalsium oksida $(\mathrm{CaO})$ dengan dilakukan transesterifikasi selama 2 jam. Penelitian ini menggunakan metode pendekatan yang digunakan adalah metode experimental dengan faktorial desain dengan dilakukan percobaan sebanyak 8 kali. Bahan baku pada penelitian biodiesel ini menggunakan minyak kelapa sawit dan metanol. Katalis yang digunakan yaitu katalis basa heterogen. Katalis heterogen lebih mudah dalam pemurnian produk biodiesel yang dapat mengurangi biaya produksi biodiesel, dapat digunakan kembali, ecofriendly dan ramah lingkungan (Sanchez et al., 2015) berupa kalsium oksida $(\mathrm{CaO})$ untuk reaksi transesterifikasi. Kalsium oksida ( $\mathrm{CaO}$ ) banyak digunakan untuk reaksi transesterifikasi karena memiliki kekuatan basa yang relatif tinggi, ramah lingkungan, kelarutan yang rendah dalam metanol dan dapat disintesis dari sumber yang murah. Pada penelitian ini digunakan variabel bebas dan variabel tetap. Variabel bebas yang digunakan adalah suhu transesterifikasi $55^{\circ} \mathrm{C}$ dan $65^{\circ} \mathrm{C}$, konsentrasi katalis 3\% dan 5\% dan \% berat metanol 30\% dan 50\%. Variabel tetapnya yaitu reaksi transesterifikasi selama 2 jam.

Reaksi transesterifikasi yang dilakukan pada pembuatan biodiesel ini menggunakan minyak kelapa sawit dengan metanol dan katalis kalsium oksida ( $\mathrm{CaO}$ ) selama 2 jam. Setelah itu dilakukan pemisahan lapisan katalis dan gliserol dari metil ester yang dihasilkan dengan menggunakan 
corong pemisah dan didiamkan selama \pm 4 jam hingga terbentuk 2 lapisan. Lapisan atas dicuci dengan ar hangat $80^{\circ} \mathrm{C}$ lalu dipisahkan sampai terbentuk 2 lapisan dan menghasilkan meti ester. Biodiesel yang dihasilkan diuji densitas, viskositas, flash point, bilangan asam dan cetane number.

\section{HASIL DAN PEMBAHASAN}

Pada transesterifikasi minyak kelapa sawit yang direaksikan dengan metanol dan katalis berupa $\mathrm{CaO}$ selain itu, pada penelitian ini menggunakan metode factorial design dengan kondisi transesterifikasi yang yang berbeda, dengan metode ini hanya membutuhkan jumlah run yang sedikit untuk mengetahui efek-efek pada variabel proses yang digunakan dan kondisi optimum yang diperoleh lebih tepat karena mengikut sertakan faktor interaksinya.

Pada penelitian ini menggunakan tiga variabel proses, yaitu suhu ( $\mathrm{t}$ ), konsentrasi katalis (k) dan \% berat metanol ( $m$ ) dengan dua level yang menghasilkan berat biodiesel dari minyak kelapa sawit dengan jumlah yang berbeda sebagai responnya dapat dilihat pada Tabel 1 .

Pada Tabel 1 menunjukkan bahwa volume minyak dan yield biodiesel yang dihasilkan memiliki nilai sesuai dengan tanda dari level variabel proses waktu transesterifikasi, penggunaan variabel suhu transesterifikasi pada level bawah $-55^{\circ} \mathrm{C}$ menghasilkan volume dan yield minyak yang lebih banyak dari level atas $65^{\circ} \mathrm{C}$. Untuk melakukan optimasi dalam penelitian ini perlu diketahui variabel proses yang sangat berpengaruh dalam penelitian ini dengan cara quicker method yaitu perhitungan main effect dan interaksi terhadap yield yang dihasilkan. Hasil perhitungan variabel yang berpengaruh dapat dilihat pada pada Tabel 2 dan 3 dan Gambar 1 .

Pada Tabel 2 menunjukan hasil bahwa dari ketiga variabel yang diteliti suhu transesterifikasi merupakan variabel yang paling mempengaruhi dalam proses transesterifikasi minyak kelapa sawit jika dilihat dari perhitungan quicker method yang menghasilkan jumlah efek paling besar.

Sedangkan pada Gambar 1 menunjukkan bahwa $x_{1}$ titik hasil perhitungan efek transesterifikasi dengan percent probability menjauh dari kerapatan. Dari hasil analisa tersebut, kita dapat langsung melakukan optimasi proses dengan variasi variabel suhu transesterifikasi $(\mathrm{t}$ ) untuk menentukan besar yield biodiesel minyak kelapa sawit.

Tabel 1. Hasil Biodiesel Minyak Kelapa Sawit Dengan Variasi Kondisi Transesterifikasi

\begin{tabular}{cccccccccc}
\hline \multirow{2}{*}{ Run } & \multicolumn{3}{c}{ Variabel Berubah } & \multicolumn{9}{c}{ Interaksi } & Volume Minyak & \multirow{2}{*}{ Yield (\%) } \\
\cline { 2 - 6 } & $\mathrm{T}$ & $\mathrm{k}$ & $\mathrm{m}$ & $\mathrm{Tk}$ & $\mathrm{Tm}$ & $\mathrm{km}$ & $\mathrm{Tkm}$ & & \\
\hline 1 & 55 & $3 \%$ & $30 \%$ & + & + & + & - & 330 & 85,33 \\
2 & 65 & $3 \%$ & $30 \%$ & - & - & + & + & 328 & 84,81 \\
3 & 55 & $5 \%$ & $30 \%$ & - & + & - & + & 338 & 87,40 \\
4 & 65 & $5 \%$ & $30 \%$ & + & - & - & - & 325 & 84,03 \\
5 & 55 & $3 \%$ & $50 \%$ & + & - & - & + & 340 & 87,91 \\
6 & 65 & $3 \%$ & $50 \%$ & - & + & - & - & 315 & 81,45 \\
7 & 55 & $5 \%$ & $50 \%$ & - & - & + & - & 335 & 86,62 \\
8 & 65 & $5 \%$ & $50 \%$ & + & + & + & + & 310 & 80,16 \\
\hline
\end{tabular}

Tabel 2. Hasil Perhitungan Main Effect dan Interaksi Terhadap Yield

\begin{tabular}{cc}
\hline Efek & Jumlah \\
\hline $\mathrm{I}_{1}, \mathrm{t}$ & $-4,20$ \\
$\mathrm{I}_{2,} \mathrm{k}$ & 0,32 \\
$\mathrm{I}_{3,} \mathrm{~m}$ & $-1,36$ \\
$\mathrm{I}_{12,} \mathrm{tk}$ & $-0,71$ \\
$\mathrm{I}_{13}, \mathrm{tm}$ & $-2,26$ \\
$\mathrm{I}_{23,} \mathrm{~km}$ & $-0,97$ \\
$\mathrm{I}_{123}, \mathrm{~km}$ & 0,71 \\
\hline
\end{tabular}


Tabel 1. Penentuan Variabel Berpengaruh

\begin{tabular}{cc}
\hline$P(\%)$ & Efek \\
\hline 7,14 & $-4,20$ \\
21,71 & $-2,26$ \\
35,71 & $-1,36$ \\
50,0 & $-0,97$ \\
64,29 & $-0,71$ \\
78,57 & $-0,32$ \\
92,86 & 0,71 \\
\hline
\end{tabular}

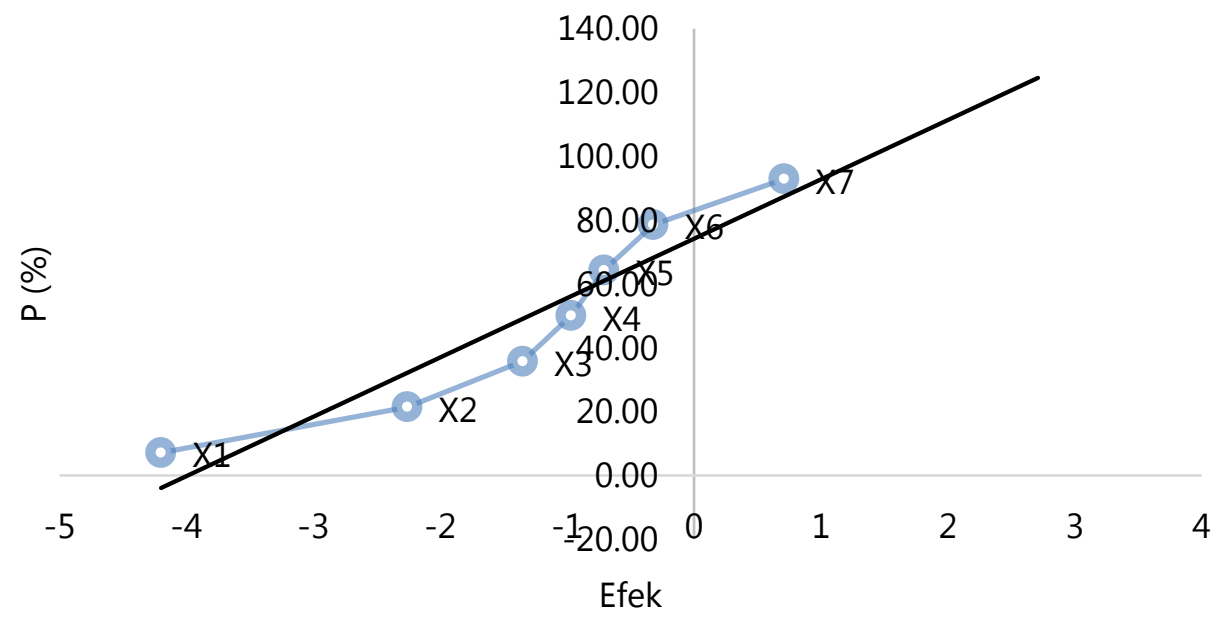

Gambar 1. Normal Probability Plot (P vs Z) untuk $2^{3}$

\section{Optimasi Transesterifikasi Biodiesel}

Dari analisa varian yang telah dilakukan dapat diketahui bahwa variabel proses yang berpangaruh pada proses penelitian transesterifikasi pada biodiesel minyak kelapa sawit adalah suhu transesterifikasi, sehingga untuk proses optimasi ini variabel $\mathrm{k}$ (konsentrasi katalis) dan $\mathrm{m}$ (\% berat metanol) menjadi variabel tetap dan variabel $t$ (suhu transesterifikasi) menjadi variabel berubah. Adapun hasil optimasi yang telah dilakukan dapat dilihat pada Tabel 4.

Pada Tabel 4 menunjukan bahwa lama suhu transesterifikasi dari $55^{\circ} \mathrm{C}$ hingga $65^{\circ} \mathrm{C}$ menghasilkan yield biodiesel yang semakin besar dan mengalami penuruna yield pada suhu transesterifikasi $63^{\circ} \mathrm{C}$ Hasil optimasi transesterifikasi minyak kelapa sawit dapat dilihat pada Gambar 2.

Berdasarkan yield biodiesel yang dihasilkan seperti yang tersaji pada Tabel 4 dan Gambar 2, dapat diketahui bahwa suhu transesterifikasi $(t)$ $60^{\circ} \mathrm{C}$ merupakan hasil yang terbaik dengan yield $89,98 \%$ dengan kondisi operasi lainnya yang optimum adalah 3\% untuk konsentrasi katalis dan $50 \%$ untuk \% berat metanol. Kenaikan suhu transesterifikasi akan mempermudah untuk terjadinya reaksi karena secara kinetika, kenaikan suhu reaksi akan meningkatkan konversi. Tetapi pada reaksi transesterifikasi ini suhu maksimum dibatasi oleh titik didih metanol. Suhu reaksi yang melebihi suhu didih metanol akan menyebabkan metanol menguap dan mengurangi jumlah metanol dalam campuran reaksi. Serta jika suhu ditingkatkan melebihi suhu optimal reaksi akan menyebabkan penurunan yield biodiesel yang disebabkan oleh tingginya suhu reaksi yang mempercepat proses saponifikasi trigliserida. Seperti halnya dengan suhu reaksi pada percobaan ke-4 yaitu $63^{\circ} \mathrm{C}$ yang tersaji pada tabel 4 dan gambar2 mengalami penurunan. Jika dibandingkan dengan penelitian yang dilakukan Hidayati (2017) yield biodiesel yang dihasilkan $53 \%$ pada suhu reaksi $60^{\circ} \mathrm{C}$, jumlah katalis $3 \%$ dan waktu reaksi 2 jam hal ini menunjukan bahwa suhu transesterifikasi berpengaruh terhadap yield biodiesel yang dihasilkan. 
Tabel 4. Yield Biodiesel Minyak Kelapa Sawit Pada Proses Optimasi

\begin{tabular}{cccc}
\hline Suhu $\left({ }^{\circ} \mathrm{C}\right)$ & Konsentrasi Katalis (\%) & \%berat metanol (\%) & Yield (\%) \\
\hline 55 & & & 87,40 \\
58 & 3 & $50 \%$ & 89,20 \\
60 & & & 89,98 \\
63 & & & 82,22 \\
65 & & & 79,90 \\
\hline
\end{tabular}

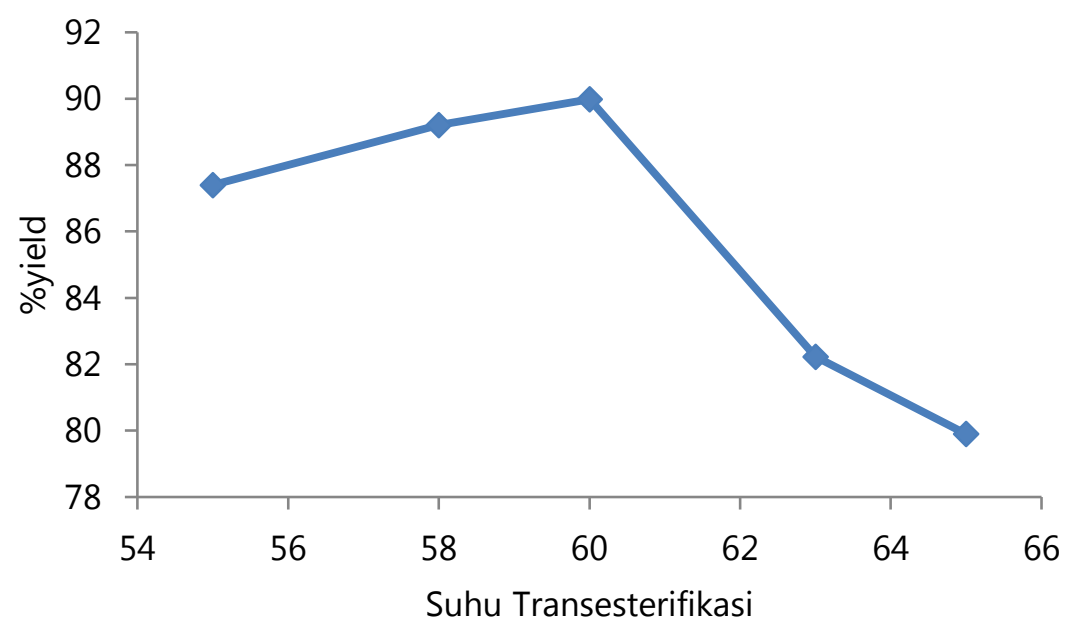

Gambar 2. Optimasi Biodiesel

Tabel 5. Hasil Analisa Biodiesel Pengaplikasian Biodiesel Minyak Kelapa Sawit

\begin{tabular}{ccc}
\hline Pengujian & Biodiesel Minyak Kelapa Sawit & Biosolar Pertamina \\
\hline Densitas $\left(\mathrm{kg} / \mathrm{m}^{3}\right)$ & 838 & $815-860$ \\
Viskositas $\left(\mathrm{mm}^{2} / \mathrm{sec}\right)$ & 4,01 & $2,0-4,5$ \\
Bilangan Asam $\mathrm{mgKOH} / \mathrm{gr}$ & 0,45 & Maks 0,6 \\
Flash Point $\left({ }^{\circ} \mathrm{C}\right)$ & 63 & Min 52 \\
Angka Setana & 48,45 & Min 48 \\
\hline
\end{tabular}

\section{Analisa Biodiesel}

Analisa yang diuji meliputi densitas, viskositas, bilangan asam, flash point dan angka setana pada variabel optimasi dengan suhu $60^{\circ} \mathrm{C}$, konsentrasi katalis $3 \%$ dan $50 \%$ berat metanol yang dibandingkan dengan spesifikasi biosolar Pertamina. Pada penelitian ini dilakukan pengaplikasian biodiesel minyak kelapa sawit B-30 menggunakan alat fogging Garda Pest Control Semarang dengan meninjau suara yang dihasilkan dari mesin fogging. Didapatkan untuk kebisingan alat fogging yaitu 79,9 dB. Dari penelitian biodiesel minyak kelapa sawit didapatkan \%kesalahannya sebesar $25 \%$ dan \%keakuratannya yaitu $75 \%$.

\section{KESIMPULAN}

Penggunaan metode factorial design dua level pada tiga variabel proses dan quicker method untuk perhitungan efek dan interaksi variabel proses dengan 8 kali run (percobaan) menghasilkan bahwa variabel proses yang sangat berpengaruh untuk proses optimasi transesterifikasi minyak kelapa sawit adalah 
variabel suhu transesterifikasi $(t)$ dengan jumlah atau nilai efek sebesar 4,20. Dari proses optimasi dengan memvariasikan suhu transesterifikasi minyak kelapa sawit menunjukan bahwa suhu transesterifikasi memberikan pengaruh nyata terhadap yield biodiesel yang dihasilkan, semakin tinggi suhu transesterifikasi maka semakin besar yield biodiesel yang dihasilkan. Suhu transesterifikasi optimum pada penelitian ini adalah $60^{\circ} \mathrm{C}$ dengan yield sebesar $89,98 \%$ untuk konsentrasi katalis $3 \%$ dan $50 \%$ berat metanol. Uji kualitas terhadap transesterifikasi biodiesel menggunakan minyak kelapa sawit memenuhi spesifikasi biosolar pertamina, yaitu densitas sebesar $838 \mathrm{~kg} / \mathrm{m} 3$ (standar Pertamina 815-860 $\mathrm{kg} / \mathrm{m} 3$ ), viskositas sebesar 4,01 mm2/sec (standar Pertamina 2,0-4,5 $\mathrm{mm} 2 / \mathrm{sec}$ ), bilangan asam sebesar $0,45 \mathrm{mgKOH} / \mathrm{gr}$ (standar Pertamina maks 0,6 ), flash point sebesar $63^{\circ} \mathrm{C}$ (standar Pertamina $\min 52^{\circ} \mathrm{C}$ ) dan angka setana sebesar 48,45 (standar Pertamina min 48). Serta uji kebisingan biodiesel (B30) minyak kelapa sawit pada mesin fogging sebesar 79,9 dB terdapat perbedaan pada kebisingan solar pada mesin fogging sebesar 81,6 $\mathrm{dB}$. Penelitian biodiesel minyak kelapa sawit didapatkan \%kesalahannya sebesar 25\% dan \%keakuratannya yaitu $75 \%$.

\section{DAFTAR PUSTAKA}

Aziz, I. 2008. Pembuatan Biodiesel Dari Minyak Goreng Bekas Dalam Reaktor Tangki Alir Berpengaduk, Jurnal Kimia Valensi, 1(2):100104. doi: 10.15408/jkv.v1i2.257.

Hidayati, N., Ariyanto, T. S.\& Septiawan, H. 2017. Transesterifikasi Minyak Goreng Bekas Menjadi Biodiesel Dengan Katalis Kalsium Oksida, Jurnal Teknologi Bahan Alam, 1(1):15.

PT. PERTAMINA (persero) 2017. Spesifikasi Solar / Biosolar, (1):17. Available at: https://www.pertamina.com/industrialfuel/me dia/6796/biosolar.pdf.

Tantra, H.D., Tandean, E., Indraswati, N. \& Ismadji, S. 2011. Prosiding Seminar Nasional Fundamental dan Aplikasi Katalis Dari Limbah Kerang Batik (Phapia undulata) Untuk Pembuatan Biodiesel dari Minyak Kelapa Sawit. Prosiding Seminar Nasional Fundamental dan Aplikasi Teknik Kimia.

Yudhistira, A. D. and Istadi, I. (2013) 'Unjuk Kerja Reaktor Plasma Dielectric Barrier Discharge Untuk Produksi Biodiesel Dari Minyak Kelapa Sawit', Teknik, 34(2):116. doi: 10.14710/teknik. v34i2.5636. 